\title{
IMPACTOS DA VIOLÊNCIA DOMÉSTICA NA SAÚDE DOS IDOSOS
}

\author{
IMPACTS OF DOMESTIC VIOLENCE ON THE HEALTH OF THE \\ ELDERLY
}

Lindemberg Arruda Barbosa ${ }^{1}$

Fihama Pires Nascimento ${ }^{2}$

Renata Clemente dos Santos ${ }^{3}$

Emanuella de Castro Marcolino ${ }^{4}$

RESUMO: Objetivo: descrever por meio da literatura os impactos da violência doméstica na saúde dos idosos. Método: revisão integrativa com abordagem qualitativa. Realizou-se duas combinações com os descritores em saúde, na primeira utilizou-se os termos "saúde", "violência doméstica" e "idoso"; sendo articulados com o operador booleano AND na base de dados Scientific Eletronic Library Online (SciELO) e na Biblioteca Virtual de Saúde (BVS), resultando em 737 trabalhos. Após o uso dos filtros, permaneceram 125, mediante a leitura dos títulos e resumos foram selecionados 7 . Na segunda busca, sucedeu-se sob os mesmos critérios de inclusão na BVS com a utilização dos descritores "violência doméstica" e "maus-tratos ao idoso". Obtendo-se 60 trabalhos, dos quais, foram selecionados 4 após a leitura completa, resultando na amostra final 11 manuscritos. Resultados: a violência doméstica em idosos ocasiona baixa qualidade de vida, ausência de apetite, desnutrição, angústia, desidratação, estresse, lesões, dor, aflição, falta de segurança, traumas físicos, emocionais e sociais, doenças psicossomáticas, isolamento, incapacidade, perda de identidade, alterações no sono, redução das defesas físicas, mortalidade, morbidade e suicídio. Conclusão: infere-se a necessidade de intervenções contra a violência doméstica perpetrada na população da terceira idade, considerando os impactos diretos e indiretos do fenômeno em todas as instâncias de saúde e social do público em discussão.

\footnotetext{
1 Discente do curso de Enfermagem na UNIFACISA Centro Universitário; E-mail: lindemberg.uf@gmail.com.

2 Discente do curso de Enfermagem na UNIFACISA Centro Universitário; E-mail: fihamapires0@gmail.com.

3 Docente do curso de Enfermagem da UNIFACISA Centro Universitário. Doutoranda em Enfermagem pela UFPB; E-mail: renata.clemente@hotmail.com.

${ }^{4}$ Docente do curso de Enfermagem da UNIFACISA Centro Universitário. Doutora em Enfermagem pela UFRN; E-mail: emanuella.de.castro@gmail.com.
} 
Palavras chave: Violência doméstica. Idoso. Saúde. Maus-Tratos ao Idoso.

ABSTRACT: Objective: To describe through the literature the impacts of domestic violence on the health of the elderly. Method: integrative review with qualitative approach. Two combinations were made with the health descriptors, in the first were used the terms "health", "domestic violence" and "elderly"; being articulated with the boolean operator "AND" in the Scientific Electronic Library Online (Scielo) and in the Virtual Health Library (BVS) resulting in 737 articles. After filtering, 125 remained, by reading the titles and abstracts, 7 of these were selected. In the second search, it was succeeded under the same inclusion criteria in the BVS with the use of the descriptors "domestic violence" and "elder abuse". Obtaining 60 articles, in which 4 were selected after full reading, resulting in the final sample 11 manuscripts. Results: domestic violence in the elderly causes low quality of life, lack of appetite, malnutrition, anguish, dehydration, stress, injuries, pain, distress, lack of security, physical, emotional and social traumas, psychosomatic diseases, isolation, disability, loss of identity, changes in sleep, reduction of physical defenses, mortality, morbidity and suicide. Conclusion: it is inferred the need for interventions against domestic violence perpetrated in the elderly population, considering the direct and indirect impacts of the phenomenon in all health and social instances of the public under discussion.

Keywords: Domestic violence; Elderly; Health; Elder abuse. 


\section{INTRODUÇÃO}

No Brasil a segunda metade do século XX pode ser compreendida por um período de grandes transformações demográficas, populacionais e epidemiológicas. As inúmeras famílias tradicionais, que eram majoritariamente rurais, passaram a adentrar o meio urbano com um novo arranjo familiar. Por consequente, sucedeu-se um aumento na expectativa de vida e uma queda na taxa de fecundidade, ocasionando no panorama atual, um grupo cada vez mais expressivo de pessoas com mais de sessenta anos de vida (LEONE; MAIA; BALTAR, 2010; VASCONCELOS; GOMES, 2012).

Para os idosos, o ambiente familiar representa: segurança, confiança e pertencimento, no qual, o apoio estável se faz necessário. Dessa forma, é na família que consiste a procura inicial pelo cuidado (ARAÚJO et al., 2012). O membro da família cuidador encarrega-se por atender às necessidades do parente idoso, viabilizando o exercício das atividades rotineiras como a higiene pessoal, alimentação, acompanhamento junto aos serviços de saúde e observância da medicação diária (GRATÃO et al., 2012).

Contudo, a literatura científica aponta o ambiente familiar como um dos principais nichos de ocorrência da violência perpetrada na população geriátrica (MANSO; COMOSAKO; LOPES, 2018), podendo ser explicada pelo possível despreparo dos cuidadores, ao assumir a responsabilidade de cuidar em caráter permanente, colocando o idoso em uma posição de desvalorização e se tornando propenso para as situações das agressões verbais, físicas, psicológicas, patrimoniais e/ou financeiras (OLIVEIRA et al., 2012).

Evidencia-se que as agressões são mais recorrentes em cenários que há um maior grau de dependência (OLIVEIRA et al., 2012), mostrando-se velada no âmbito familiar, uma vez que, as vítimas comumentes não denunciam os agressores em virtude do medo, da retaliação, sensação de vergonha, incapacidade de se defender 
e ausência do conhecimento sobre os programas de assistência e proteção (WANDERBROOCKE; MORÉ, 2013).

Lamentavelmente, os inúmeros maus-tratos cometidos na população da terceira idade são subnotificados na sociedade brasileira, especialmente por sua ocorrência ser mais prevalente no contexto familiar (RODRIGUES et al., 2017), apesar das agressões deixarem graves consequências na saúde das vítimas, principalmente para aquelas que omitem o abuso.

Mediante o exposto, questiona-se: quais os impactos para a saúde do idoso vítima de violência elencados na literatura científica? Diante desse contexto, o estudo tem o objetivode descrever por meio da literatura os impactos na saúde dos idosos vítimas de violência doméstica.

\section{MÉTODO}

Trata-se de uma revisão integrativa de literatura com abordagem qualitativa. Inicialmente determinou-se a questão norteadora seguindo a estratégia de PICo, em que $P$ (paciente) refere-se aos idosos vítimas de violência doméstica; I (interesse) os impactos que as agressões ocasionam na saúde da população geriátrica; Co (contexto) a literatura científica.

Subsequentemente foram selecionados os descritores "saúde", "idoso" e "violência doméstica" na plataforma Descritores em Ciências da Saúde (DeCS) e mediados com operador booleano AND na Biblioteca Virtual de Saúde (BVS) e na base de dados ScientificEletronic Library Online (SciELO).

A princípio foram encontrados 737 artigos, sendo; 687 na BVS e 50 na SciELO, apósaplicação dos filtros: idioma em português e recorte temporal de 8 anos, restaram 125 trabalhos, os quais foram submetidos a leitura dos títulos e resumos sendo descartados os que não condiziam com o objetivo da pesquisa e os que estavam anexados mais de uma vez na mesma plataforma, perfazendo a primeira amostra com 7 manuscritos. 
Objetivando agregar mais dados ao estudo, foi realizada uma nova busca, sobre o mesmo recorte temporal e filtro na BVS; com a utilização dos descritores "violência doméstica" e "maus-tratos ao idoso". Na qual, obteve-se 60 trabalhos, mediante a leitura completa, foram selecionados 4 . Sendo assim, compôs a amostra final 11 artigos.

Fluxograma 1 - Detalhamento das etapas da pesquisa na Biblioteca Virtual de Saúdee na base de dados Scientific Eletronic Library Online.

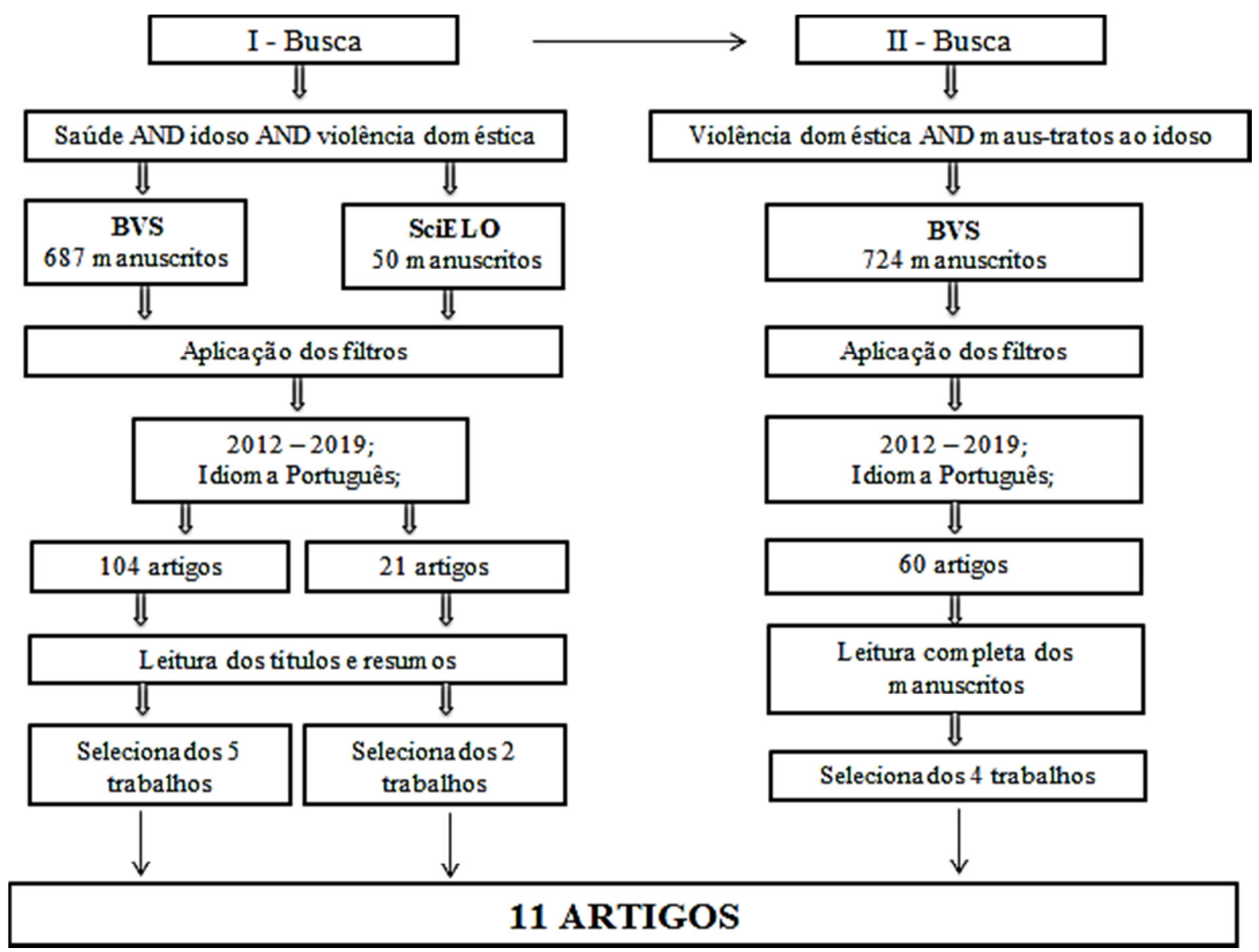

Fonte: Elaborado pelos autores. 


\section{RESULTADOS}

Nos quadros adiante há informações sobre os artigos que compuseram a amostra, no qual foram codificados de acordo com o ano de publicação, seguindo uma sequência crescente.

No quadro 1, destaca-se: autores, ano de publicação, tipo e abordagem dos estudos. Pode-se observar que os artigos científicos selecionados predominam as pesquisas com abordagem quantitativa, quanto à tipologia variam entre: descritivo, retrospectivo, transversal, inquérito domiciliar, analítico, observacional, documental, populacional e epidemiológico.

Os manuscritos escolhidos há uma predominância das publicações no ano de 2015 com 27,27 \%, seguido de 2012, 2016 e 2018 com 18,18 \%. Os anos 2013 e 2014 obtiveram amesma prevalência na amostra com 9,09 \%.

Quadro 1 - Descrição dos autores, ano de publicação, tipos e abordagem dos artigos científicos selecionados na SciELO e BVS, Campina Grande - PB.

\begin{tabular}{|c|c|c|c|}
\hline $\begin{array}{l}\text { Código do } \\
\text { manuscrito }\end{array}$ & Autor & Ano & $\begin{array}{c}\text { Tipo de estudo/abordagem do } \\
\text { estudo }\end{array}$ \\
\hline L1 & $\begin{array}{l}\text { MASCARENHAS, M. D. } \\
\text { M. et al. }\end{array}$ & 2012 & $\begin{array}{l}\text { Estudo descritivo, retrospectivo } \\
\text { com abordagem quantitativa. }\end{array}$ \\
\hline L2 & $\begin{array}{l}\text { ABATH, M. B.; LEAL, M. } \\
\text { C. C.; FILHO, D. A.M. }\end{array}$ & 2012 & $\begin{array}{l}\text { Pesquisa de corte transversal } \\
\text { comabordagem quantitativa. }\end{array}$ \\
\hline L3 & $\begin{array}{l}\text { PINTO, F. N. F. R.; } \\
\text { BARHAM, } \\
\text { ALBUQUERQUE, P.P. }\end{array}$ & 2013 & $\begin{array}{l}\text { Estudo transversal } \\
\text { abordagemquantitativa. }\end{array}$ \\
\hline L4 & SILVA, R. F. et al. & 2014 & $\begin{array}{l}\text { Pesquisa descritiva, } \\
\text { abordagem quantitativa. }\end{array}$ \\
\hline L5 & $\begin{array}{l}\text { PAIVAL, } \quad \text { M. } \\
\text { TAVARES, D.M. S. }\end{array}$ & 2015 & $\begin{array}{l}\text { Inquérito domiciliar, analítico, } \\
\text { observacional, transversal com } \\
\text { abordagem quantitativa. }\end{array}$ \\
\hline L6 & AGUIAR, M. P. C. et al. & 2015 & $\begin{array}{l}\text { Estudo descritivo documental } \\
\text { com abordagem quantitativa. }\end{array}$ \\
\hline $\mathrm{L} 7$ & $\begin{array}{l}\text { GRILO, P. } \\
\text { JÚNIOR, I.L. }\end{array}$ & 2015 & $\begin{array}{l}\text { Revisão de literatura } \\
\text { abordagem qualitativa. }\end{array}$ \\
\hline L8 & BOLSONI, A. & 2016 & $\begin{array}{l}\text { Estudo transversal } \\
\text { abordagem quantitativa. }\end{array}$ \\
\hline
\end{tabular}




\begin{tabular}{|c|l|c|l|}
\hline L9 & $\begin{array}{l}\text { SILVA, C. F. S; DIAS, C. } \\
\text { M. S. B }\end{array}$ & 2016 & $\begin{array}{l}\text { Pesquisa descritiva com } \\
\text { abordagem qualitativa. }\end{array}$ \\
\hline L10 & $\begin{array}{l}\text { GUIMARÃES, A. P. S. Et } \\
\text { al. }\end{array}$ & 2018 & $\begin{array}{l}\text { Estudo transversal, descritivo, } \\
\text { retrospectivo com abordagem } \\
\text { quantitativa. }\end{array}$ \\
\hline L11 & SOUZA, C. S. et al. & 2018 & $\begin{array}{l}\text { Estudo do tipo populacional ou } \\
\text { epidemiológico, descritivo, } \\
\text { observacional, transversal e com } \\
\text { abordagem quantitativa. }\end{array}$ \\
\hline
\end{tabular}

Fonte: Elaborado pelos autores.

No quadro 2 retrata os achados da pesquisa, no qual, nota-se que a população geriátrica quando submetida à violência pode apresentar diversas patologias físicas como problemas reumatológicos, desnutrição, desidratação, perda da mobilidade e lesões, como também danos psicológicos destacando-se as doenças psicossomáticas, isolamento e a depressão, fomentando, consequentemente, a morbidade e mortalidade.

Quadro 2 - Descrição dos trabalhos quanto aos seus objetivos e os impactos que a violência produziu na saúde da população geriátrica, Campina Grande - PB.

\begin{tabular}{|c|c|c|}
\hline $\begin{array}{l}\text { Código do } \\
\text { manuscrito }\end{array}$ & Objetivo dos estudos & $\begin{array}{l}\text { Os impactos que a violência } \\
\text { produziu na saúde do idoso }\end{array}$ \\
\hline L1 & 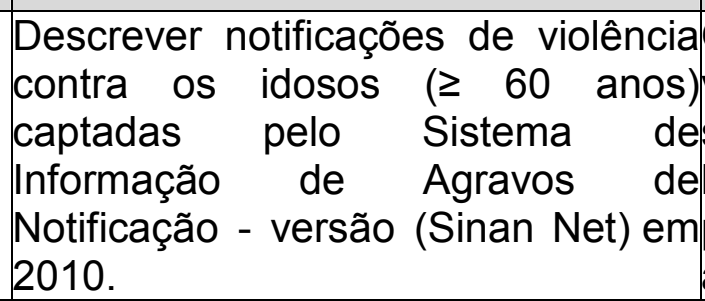 & $\begin{array}{l}\text { Ocasiona a baixa qualidade de } \\
\text { vida, lesões, dor, aflição, falta de } \\
\text { segurança, perda dos direitos } \\
\text { humanos, traumas e estresse } \\
\text { psicológico, assim como favorece } \\
\text { a mortalidade e morbidade. }\end{array}$ \\
\hline L2 & $\begin{array}{l}\text { Determinar os fatores associados à } \\
\text { violência doméstica do tipofísica em } \\
\text { idosos submetidos a exame de } \\
\text { corpo de delito, entre } 2004 \text { e } 2007 \text {, } \\
\text { no Instituto de Medicina Legal do } \\
\text { Recife. }\end{array}$ & $\begin{array}{l}\text { Lesões, morte, danos } \\
\text { psicológicos, deficiência de } \\
\text { desenvolvimento das atividades } \\
\text { diárias e privação. }\end{array}$ \\
\hline L3 & $\begin{array}{l}\text { Levantar qual o tipo mais comum de } \\
\text { violência contra idosos, comparar o } \\
\text { perfil dos idosos que sofreram } \\
\text { violência doméstica com idosos da } \\
\text { população geral e levantar quais } \\
\text { foram seus principais agressores. }\end{array}$ & $\begin{array}{l}\text { Machucados, dor, incapacidade, } \\
\text { morte, sofrimento, angústia, } \\
\text { isolamento, lesões, traumas } \\
\text { físicos, emocionais e sociais. }\end{array}$ \\
\hline
\end{tabular}




\begin{tabular}{|c|c|}
\hline L4 & $\begin{array}{l}\text { Descrever o perfil das notificações } \\
\text { de violência contra idosos na| Frustração, depressão etraumas. } \\
\text { Microrregião de Senhor do Bonfim. }\end{array}$ \\
\hline L5 & 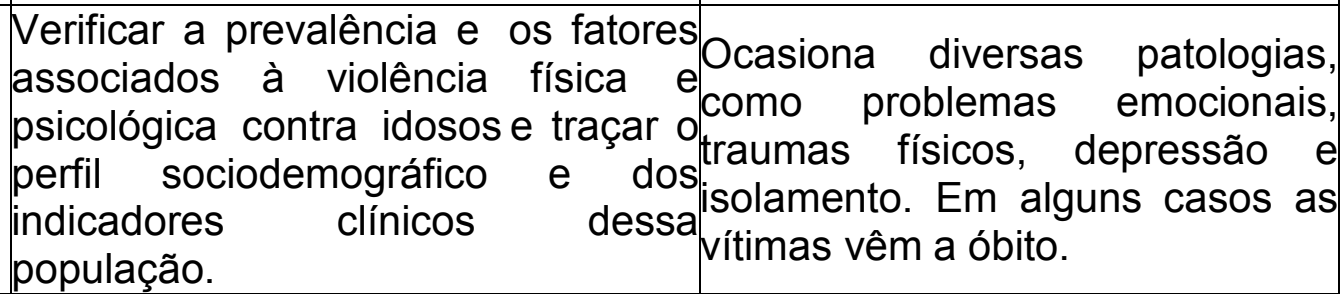 \\
\hline L6 & 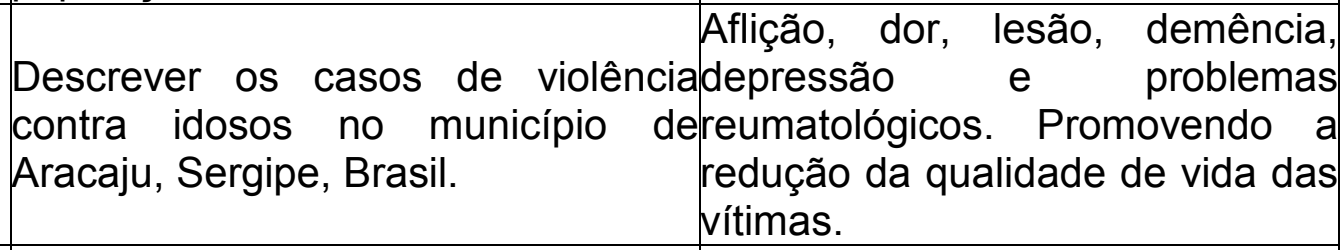 \\
\hline $\mathrm{L} 7$ & $\begin{array}{l}\text { Identificar quais as causas de maus- } \\
\text { tratos em idosos, onde ocorrem elMorte, lesão, dano psicológico, } \\
\text { quais as pessoas responsáveis pordeficiência no desenvolvimento e } \\
\text { esses maus- tratos e a atuação dos privação. } \\
\text { profissionais em relação a isso. }\end{array}$ \\
\hline L8 & 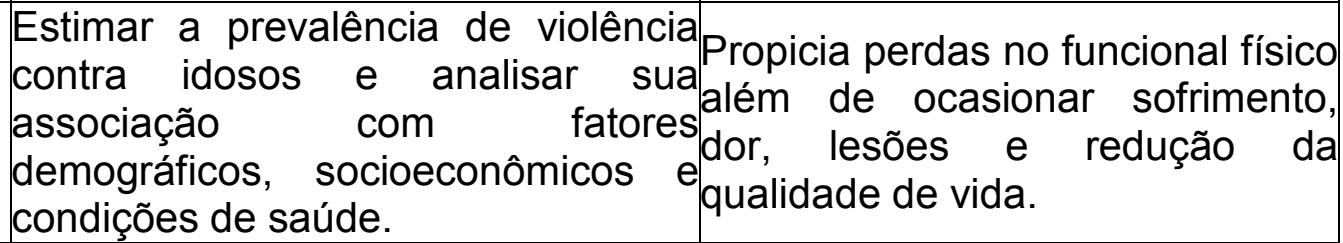 \\
\hline L9 & 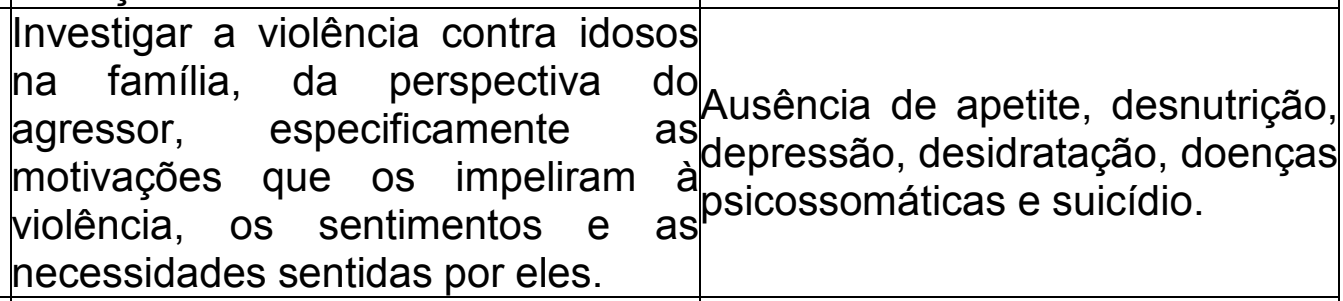 \\
\hline L10 & $\begin{array}{l}\text { Caracterizar a população de idosas } \text { Desordena a saúde física e } \\
\text { que sofreram violência sexual emental das vítimas gerando } \\
\text { física e descrever astraumas morais, físicos e } \\
\text { características dessa agressão. }\end{array}$ \\
\hline L11 & $\begin{array}{l}\text { Analisar estatisticamente o númerolidentidade, alterações no sono e } \\
\text { de internações e mortalidade por no apetite, fadiga, patologias } \\
\text { agressão em pacientes idosos nopsicossomáticas, redução das } \\
\text { ano de } 2016 \text {, por região brasileira, defesas físicas, depressão, } \\
\text { tendo em vista a carência de dados desidratação, desordem pós- } \\
\begin{array}{l}\text { a este respeito na literaturatraumática, desnutrição, agitação, } \\
\text { especializada. }\end{array} \\
\text { tentativas de suicídio e até a } \\
\text { morte. }\end{array}$ \\
\hline
\end{tabular}

Fonte: Elaborado pelos autores. 


\section{DISCUSSÃO}

A violência contra o idoso é considerada um grande problema de saúde pública no Brasil, uma vez que promove embates nas esferas previdenciárias e assistenciais, assim como no âmbito da segurança pública, incidindo de forma negativa na saúde dos cidadãos na terceira idade (REICHENHEIM et al., 2011).

A população geriátrica necessita de cuidados específicos em decorrência das suas limitações e vulnerabilidade. Dessa maneira, o despreparo dos cuidadores favorece o episódio da violência, fator esse, que mostra a necessidade de uma expansão na instrução desse grupo para que possam compreender o fenômeno do envelhecimento, desmistificando a concepção de que a população idosa é um fardo social. É substancial que o cuidador se mantenha preparado para criar condições que estimulem um envelhecimento ativo, melhorando a qualidade de vida dos idosos (JÚNIOR et al., 2011).

A família desempenha um papel fundamental no processo do envelhecimento, nota-se que mesmo que o idoso não necessite do auxílio na resolução das atividades diárias, a presença e participação dos familiares acarretam o bem-estar e conforto biopsicossocial, propiciando as interações e concepção da atenção, cuidado, proteção e intimidade. Fatores esses que são essenciais no arranjo harmônico familiar (AZEVEDO; MODESTO, 2016).

Segundo Silva e Dias (2016), em sua pesquisa, em que participaram 13 agressores familiares dos idosos, foi observado que $76,92 \%$ dos participantes apresentavam a "proximidade física" com as vítimas. Esse fato confirma os estudos que indicam essa condição como associada à violência contra o idoso. O convívio familiar entre as gerações, tem se intensificado pelo desemprego e o crescente número de separações/divórcios fomentando o retorno dos filhos a moradia dos pais, desencadeando a dependência e os problemas financeiros, bem como situações de conflitos e embates (ARAÚJO et al., 2012; FIGUEIREDO et al., 2010; NOGUEIRA et al., 2011). 
As interações sociais com os familiares nem sempre são caracterizadas pela beneficência, dado que, a maior parte das situações de violência contra a população idosa ocorre no ambiente doméstico (MANSO; COMOSAKO; LOPES, 2018).

No que tange os impactos oriundos das agressões, ressalta-se os danos psicológicos que são marcados pelo sofrimento moral em decorrência dos xingamentos, humilhações e insultos. Podendo desencadear, gradualmente, problemas como a ansiedade, depressão, medo, insegurança, perda da autoestima e frustração; com o decorrer do tempo as ofensas tendem a se intensificar alcançando a violência física (CUNHA; SOUSA, 2017).

Os traumas físicos são caracterizados pelas lesões musculares, que podem ser relacionadas por estiramentos, contusões e lacerações, que são facilmente visualizadas na superfície do músculo onde trabalham cruzando as articulações (FERNANDES et al., 2011), essas lesões podem fomentar interinamente a incapacidade física dos idosos. Em conformidade com Aguiar e outros (2015) há uma maior recorrência das doenças reumatologicas e a depressão nos idosos vítimas da violência.

Os problemas com a autoestima, o medo e os sentimentos de culpa oriundos das agressões, podem afetar emocionalmente as vítimas sufocando-as em pensamentos destrutivos, favorecendo cenários como a depressão e a disfunção nutricional, podendo ocasionar a idealização de cometer o suicídio (SILVA; ASSUMPÇÃO, 2018).

Observa-se que a desnutrição associada à desidratação, quando não relacionadas às patologias e condições fisiológicas proveniente da idade, pode ocasionar perdas consideráveis de peso e debilidade física. Segundo Almeida et al., (2013); Strobl et al., (2013) e Souza et al.,(2014) o desequilíbrio nutricional favorece o aumento do número de internações dos idosos, da morbimortalidade, incapacidade funcional, bem como suscita o surgimento das infecções frente à vulnerabilidade do organismo e, consequentemente, acarreta o aumento da mortalidade desse grupo.

Destaca-se que as interações sociais são essenciais no processo do envelhecimento uma vez que proporcionam impactos positivos na manutenção da saúde e qualidade de vida. No entanto os idosos vivenciam constantemente o 
isolamento social que surge em decorrência da privação da liberdade posto pelo agressor, sendo considerado em diversas pesquisas, um grande problema que afeta negativamente a saúde dessa população (MANSO; COMOSAKO; LOPES, 2018; NETTO et al., 2016).

Alguns estudos relacionam o estresse decorrente do isolamento, com 0 aumento do declínio funcional, dos níveis hormonais e o surgimento das inflamações, o que pode fomentar gradualmente o risco de diabetes tipo 2 e doenças cardíacas lacerando a qualidade de vida do idoso (MANSO; COMOSAKO; LOPES, 2018).

A "percepção do indivíduo de sua posição na vida em relação ao contexto e sistemas de valores nos quais se insere bem como seus objetivos, expectativas, padrões e preocupações" referem-se ao conceito do termo qualidade de vida (CAMPOS et al., 2015). Dessa forma, a integridade mental e física, a segurança financeira, independência e interações sociais são fatores que corroboram na qualidade de vida da população na terceira idade.

\section{CONCLUSÃO}

Nota-se que esse assunto traz consigo diversos impasses que perpassam desde as condições em que os idosos e os cuidadores se encontram. Dessa forma, conclui-se que a família tem um papel primordial na manutenção da saúde e qualidade de vida dos idosos e por isso os profissionais de saúde precisam se manter atentos às relações familiares, uma vez que estes são os principais agressores.

Algumas limitações da pesquisa devem ser ponderadas na observância dos resultados deste estudo, dado que, há uma escassez na quantidade de manuscritos que enfoquem especificamente as consequências decorrentes da violência doméstica contra o idoso. Apesar disso, os achados desta análise oferecem aos profissionais da saúde, que lidam com a população geriátrica, subsídios para construção, expansão e discussão dos conhecimentos a respeito da temática, 
contribuindo dessa forma na formulação de novas estratégias de intervenção no enfrentamento da violência, tencionando a rapidez e eficácia no diagnóstico e resolução das ocorrências.

\section{REFERÊNCIAS BIBLIOGRÁFICAS}

ABATH, M.B.; LEAL, M.C.C.; FILHO, D.A.M., Fatores associados à violência doméstica contra a pessoa idosa. Rev. bras. geriatr. gerontol., Rio de Janeiro, v. 15, n. 2, p. 305- 314, 2012. Disponível em: <http://www.scielo.br/scielo.php?script=sci_arttext\&pid=S180998232012000200013\&Ing=en\&nrm=iso>. Acesso em: 24 de jan. de 2020.

AGUIAR, M.P.C. et al., Violência contra idosos: descrição de casos no Município de Aracaju, Sergipe, Brasil. Esc. Anna Nery, Rio de Janeiro, v. 19, n. 2, p. 343-349, jun. 2015. Disponível em: $<$ http://www.scielo.br/scielo.php?script=sci_arttext\&pid=S1414$81452015000200343 \&$ Ing=en\&nrm=iso>. Acesso em 24 de jan. 2020.

ALMEIDA M.F. et al., Anthropometric changes in the Brazilian cohort of older adults: SABE Survey (Health, Well-Being, and Aging). J Obes 2013; 2013:695496.

ARAÚJO, C.K.; CARDOSO, C.M.C.; MOREIRA, E.P.; WEGNER, E.; AREOSA, S.V.C., Vínculos familiares e sociais nas relações dos idosos. Revista Jovens Pesquisadores, Santa Cruz do Sul, n. 1, p. 97-107, jun. 2012. ISSN 2237-048X. Disponível em: <https://online.unisc.br/seer/index.php/jovenspesquisadores/article/view/2868>. Acesso em: 15 fev. 2020.

ARAÚJO, L.F. et al., Violência contra a pessoa idosa: representações sociais entre adolescentes do Arquipélago de Fernando de Noronha-PE. Psicologia \& Sociedade, Belo Horizonte, v. 24, n. 1, p., 104-111, abril 2012. Disponível em: $<$ http://www.scielo.br/scielo.php?script=sci_arttext\&pid=S0102-

71822012000100012\&Ing=en\&nrm=iso>. Acesso em: 15 de fev. de 2020.

AZEVEDO, P.A.C.; MODESTO, C.M.S.A. (re)organização do núcleo de cuidado familiar diante das repercussões da condição crônica por doença cardiovascular. Rev. Saúde em Debate, Rio de Janeiro, v. 40, n. 110, p. 183-194, setembro 2016. Disponível em: <http://www.scielo.br/scielo.php?script=sci_arttext\&pid=S0103-

11042016000300183\&lng=en\&nrm=iso>. Acesso em: 15 de fev. de 2020.

BOLSONI, A.C. et al., Prevalência de violência contra idosos e fatores associados, estudo de base populacional em Florianópolis, SC. Rio de Janeiro. Rev. Bras. Geriatr. Gerontol, Riode Janeiro, v. 19, n. 4, p. 671-682, agosto $2016 . \quad$ Disponível em:

$<$ http://www.scielo.br/scielo.php?script=sci_arttext\&pid=S1809-

98232016000400671\&lng=en\&nrm=iso>. Acesso em: 15 de fev. de 2020.

CAMPOS, A.C.V; FERREIRA, E.F; VARGAS, A.M.D., Determinantes do envelhecimentoativo segundo a qualidade de vida e gênero. Ciência \& Saúde Coleta, Rio de Janeiro, v. 20, n. 7 , p. 2221-2237, julho $2015 . \quad$ Disponível em: <http://www.scielo.br/scielo.php?script=sci_arttext\&pid=S1413-

$81232015000702221 \&$ Ing=en\&nrm=iso>. Acesso em: $18 \mathrm{de} \mathrm{fev.} \mathrm{de} 2020$.

CUNHA, T.R.A; SOUSA, R.C.B., Violência psicológica contra a mulher: dor invisível. In V Congresso internacional enlaçando sexualidades, V. 1, 2017, ISSN 2238-9008, Disponível 
em:<https://www.editorarealize.com.br/revistas/enlacando/trabalhos/TRABALHO_EV072_ MD1_SA2_ID848_19062017202106.pdf>. Acesso em: 01 de fevereiro de 2020.

FERNANDES, T.L.; PEDRINELLI, A.; HERNANDEZ, A. J., Lesão muscular: fisiopatologia, diagnóstico, tratamento e apresentação clínica. Rev. bras. ortop., São Paulo, v. 46, n. 3, p. 247-255, 2011. Disponível em: $<$ http://www.scielo.br/scielo.php?script=sci_arttext\&pid=S0102-

36162011000300003\&Ing=en\&nrm=iso>. Acesso em: $01 \mathrm{de} \mathrm{fev.} \mathrm{de} 2020$.

FIGUEIREDO, A.E.B.; SOUZA, E.R.; NJAINE, K.; RIBEIRO, A.P., Violência contra a pessoa idosa. In M.V. Berzins, \& W. Malagutti (Eds.), Rompendo o silêncio: faces da violência na velhice (pp.109-121). São Paulo 2010, SP: Martinari.

GRATÃO, A.C.M. et al., Sobrecarga e desconforto emocional em cuidadores de idosos. Texto contexto - enferm., Florianópolis, v. 21, n. 2, p. 304-312, jun. 2012. Disponível em: $<$ http://www.scielo.br/scielo.php?script=sci_arttext\&pid=S0104-

$07072012000200007 \&$ Ing=en\&nrm=iso >. Ácesso em: 01 de fev. de 2020.

GRILO, P.M.S; JÚNIOR, I.L., Maus-tratos a idosos: perfil das vítimas, vínculo com o agressor e atuação dos profissionais. Estud. interdiscipl. envelhec., Porto Alegre, v. 20, n. 2, p. 611-624, 2015. Disponível em: <file:///C:/Users/Nete/Downloads/50955-245629-1-PB\%20(1).pdf>. Acesso em: 01 de fev. de 2020.

GUIMARÃES, A.P.S. et al., Notificação de violência intrafamiliar contra mulheres idosas na cidade de São Paulo. Rev. bras. geriatr. gerontol, Rio de Janeiro, v. 21, n. 1, p. 88-94, fevereiro 2018. Disponível em: <http://www.scielo.br/scielo.php?script=sci_arttext\&pid=S1809$98232018000100088 \&$ Ing=en\&nrm=iso >. Acesso em: 03 de fev. de 2020.

JÚNIOR, P.R.R. et al., Efeito da capacitação dos cuidadores informais sobre a qualidade de vida de idosos com déficit de autocuidado. Ciênc. saúde coletiva, Rio de Janeiro, v. 16, n. 7 , p.3131-3137, julho $2011 . \quad$ Disponível em: $<$ http://www.scielo.br/scielo.php?script=sci_arttext\&pid=S1413-

$81232011000800013 \&$ Ing=en\&nrm=iso >. Acesso em: 03 de fev. de 2020.

LEONE, E.T.; MAIA, A.G.; BALTAR, P.E., Mudanças na composição das famílias eimpactos sobre a redução da pobreza no Brasil. Econ. soc., Campinas, v. 19, n. 1, p. 59-77, abr. 2010. Disponível em: <http://www.scielo.br/scielo.php?script=sci_arttext\&pid=S0104$06182010000100003 \&$ Ing=en\&nrm=iso >. Acesso em: 03 de fev. de 2020.

MANSO, M.E.G; COMSOSAKO, V.T; LOPES, R.G.C., Idosos e isolamento social: algumas considerações. Revista Portal de Divulgação, n.58, ano IX. Out/Nov/Dez. 2018. ISSN 21783454. Disponível em: <file:///C:/Users/Nete/Downloads/750-1168-1-SM.pdf>. Acesso em: 20 de fev. de 2020.

MASCARENHAS, M.D.M. et al., Violência contra a pessoa idosa: análise das notificações realizadas no setor saúde - Brasil, Ciência \& Saúde Coletiva, Rio de Janeiro, v. 17, n. 9, p. 2331-2341, set. $2012 . \quad$ Disponível em: <http://www.scielo.br/scielo.php?script=sci_arttext\&pid=S1413-

$81232012000900014 \&$ Ing=en\&nrm=iso>. Acesso em: 20 de fev. de 2020.

NETTO, L.A. et al., Isolamento de mulheres em situação de violência pelo parceiro íntimo: uma condição em redes sociais. Esc Anna Nery 2017, Rio de Janeiro, v. 21, n. 1, e20170007, out. 2016. Disponível em: <http://www.scielo.br/scielo.php?script=sci_arttext\&pid=S1414$81452017000100207 \&$ Ing=en\&nrm=iso>. Acesso em: 15 de fev. de 2020.

NOGUEIRA, C.F., FREITAS, M.C., \& ALMEIDA, P.C., Violência contra idosos no município de Fortaleza, CE: uma análise documental. Revista Brasileira de Geriatria e Gerontologia, Rio de Janeiro, v. $14, \quad$ n. $3, \quad$ p. 543-554, 2011. Disponível em: 
$<$ http://www.scielo.br/scielo.php?script=sci_arttext\&pid=S1809-

98232011000300014\&lng=en\&nrm=iso>. Acesso em: 05 de abril de 2020.

OLIVEIRA, M.L.C. et al., Características dos idosos vítimas de violência doméstica no Distrito Federal. Rev. bras. geriatr. gerontol., Rio de Janeiro, v. 15, n. 3, p. 555-566, setembro 2012. Disponivel em: <http://www.scielo.br/scielo.php?script=sci_arttext\&pid=S180998232012000300016\&lng=en\&nrm=iso>. Acesso em: 05 de abril de 2020.

PAIVAL, M.M.; TAVARES, D.M.S., Violência física e psicológica contra idosos: prevalência e fatores associados. Rev. Bras. Enfermagem, Brasília, v. 68, n. 6, p. 1035- 1041, dez. 2015. Disponível em: <http://www.scielo.br/scielo.php?script=sci_arttext\&pid=S0034$71672015000601035 \&$ Ing=en\&nrm=iso>. Acesso em: 05 de abril de 2020.

PINTO, F.N.F.R.; BARHAM, E.J.; ALBUQUERQUE, P.P., Idosos vítimas de violência: dores sociodemográficas e subsídios para futuras intervenções. Euestudei. pesquisa. psicol. Rio de Janeiro, v. 13, n. 3, p. 1159-1181, dez. 2013. Disponível em: $<$ http://pepsic.bvsalud.org/scielo.php?script=sci_arttext\&pid=S1808-

$42812013000300018 \&$ Ing=es\&nrm=iso>. Acesso em 06 de abril de 2020.

REICHENHEIM, M.E. et al., Violence and injuries in Brazil: the effect, progress made, and challenges ahead. V 337, ISSUE, 1962-1975, junho 2011. Disponível em: <https://www.sciencedirect.com/science/article/pii/S0140673611600536>. Acesso em: 06 de abril de 2020.

RODRIGUES, R.A.P. et al., Violência contra idosos em três municípios brasileiros. Rev. Bras. Enferm. Brasília, v.70, n. 4, p. 783-791, agosto 2017. Disponível em: $<$ http://www.scielo.br/scielo.php?script=sci_arttext\&pid=S0034-

71672017000400783\&Ing=en\&nrm=iso>. Acesso em: 06 de fevereiro de 2020.

SILVA, C.F.S.; DIAS, C.M.S.B., Violência Contra Idosos na Família: Motivações, Sentimentos e Necessidades do Agressor. Psicol. cienc. prof., Brasília, v. 36, n. 3, p. 637- 652, setembro 2016. Disponível em: <http://www.scielo.br/scielo.php?script=sci_arttext\&pid=S141498932016000300637\&lng=en\&nrm=iso>. Acesso em: 06 de abril de 2020.

SILVA, C.F.S.; DIAS, C.M.S.B., Violência Doméstica contra idosos: Escutando o Agressor. Psicologia: Ciência e Profissão, jul/set. 2016 v. $36 n^{\circ} 3$, 637-652. Disponível em: < https://www.scielo.br/pdf/pcp/v36n3/1982-3703-pcp-36-3-0637.pdf>. Acesso em: 10 de abril de 2020.

SILVA, P.C.M; ASSUMPÇÃO, A.A., Relação entre violência psicológica e depressão em mulheres: revisão narrativa. Pretextos - Revista da Graduação em Psicologia da PUC Minas. V. 3, n. 6, jul./dez. 2018 - ISSN 2448-0738. Disponível em: $<$ http://periodicos.pucminas.br/index.php/pretextos/article/view/18408>. Acesso em: 10 de abril de 2020.

SILVA, R.F. et al., O perfil da violência notificada contra idosos na microrregião de Senhor do Bonfim - BA. C\&D-Revista Eletrônica da Fainor, Vitória da Conquista, v.7, n.1, p.171- 183, jan./jun. $2014 . \quad$ Disponível em: <http://srv02.fainor.com.br/revista/index.php/memorias/article/view/266/180>. Acesso em: $10 \mathrm{de}$ abril de 2020.

SOUSA, K.T. et al., Baixo peso e dependência funcional em idosos institucionalizados de Uberlândia (MG), Brasil. Ciênc. saúde coletiva, Rio de Janeiro, v. 19, n. 8, p. 3513-3520, agosto 2014. Disponível em: <http://www.scielo.br/scielo.php?script=sci_arttext\&pid=S1413$81232014000803513 \&$ Ing=en\&nrm=iso>. Acesso em: 12 de abril de 2020.

SOUZA, C.S.; BANDEIRA, L.L.; NASPOLINI, M.M.; AGUIAR, M.C.; MARCOLLA, V.; NETO J.D.S. Análise das taxas de internação e de mortalidade por agressão em pacientes commais 
de 60 anos. Rev Soc Bras Clin Med. 2018 abr-jun;16(2):89-93. Disponível em: <http://docs.bvsalud.org/biblioref/2018/09/913365/16289-93.pdf>. Acesso em: 12 de abril de 2020.

STROBL, R., et al., Distribution and determinants of functioning and disability in aged adultsresults from the German KORA-Age study. BMC Public Health, 13137 (2013). Disponível em: <https://bmcpublichealth.biomedcentral.com/articles/10.1186/1471-2458-13- 137\#citeas>. Acesso em: 15 de abril de 2020.

VASCONCELOS, A.M.N.; GOMES, M.M.F., Transição demográfica: a experiência brasileira. Epidemiol. Serv. Saúde, Brasília, v. 21, n. 4, p. 539-548, dez. 2012. Disponível em<http://scielo.iec.gov.br/scielo.php?script=sci_arttext\&pid=S1679-

49742012000400003\&lng=pt\&nrm=iso>. Acesso em: 15 de abril de 2020.

WANDERBROOCKE, A.C.N.S.; MORÉ, C.L.O.O., Abordagem profissional da violência familiar contra o idoso em uma unidade básica de saúde. Cad. Saúde Pública, Rio de Janeiro, v. 29,
n.
12 ,
p.
2513-2522,
dez.
2013.
Disponível
em:

<http://www.scielo.br/scielo.php?script=sci_arttext\&pid=S0102-

311X2013001200015\&lng=en\&nrm=iso>. Acesso em: 15 de abril de 2020. 